\title{
HSCT FOR NON-HODGKIN LYMPHOMA
}

\author{
Renata Baldissera', Abrahão E. Hallack Neto ${ }^{1}$, Renato Castro ${ }^{3,4,5}$ Guilherme Perrini ${ }^{6,7}$, Leandro de \\ Pádua Silva ${ }^{8,9}$, Carlos Chiattone ${ }^{10,11}$ \\ 1 Faculdade de Medicina de Marilia (FAMEMA), Marília-SP - 2 Faculdade de Medicina da Universidade Federal de Juiz de \\ Fora/Hospital Universitário UFJF - 3 CEMO/INCA Instituto Nacional do Cancer, Rio de Janeiro, RJ - 4 Hospital Quinta DÒr \\ 5 Clínica São Vicente - 6 Hospital Israelita Albert Einstein - 7 Americas Oncologia - 8 Hospital Santa Cruz - 9 Hospital Lê Forte \\ 10 Santa Casa de São Paulo - 11 Hospital Samaritano - SP
}

\section{DIFFUSE LARGE B-CELL LYMPHOMA (DLBCL):}

The addition of rituximab to the CHOP chemotherapy protocol (cyclophosphamide, doxorubicin, vincristine and prednisone) significantly improved the results for patients with DLBCL, the most frequent subtype of non-Hodgkin's lymphomas (NHL) [1]. However, there is a subgroup of patients with a worse prognosis [2] identified by the international prognostic index (IPI), where survival rates remain around $50 \%$. Efforts have been made to improve R-CHOP including increasing dose density with 14day cycles, the use of obinutuzumab, or intensifying therapy such as the DA-EPOCH protocol, but with no definitive clinical benefits [3]. Biological agents such as ibrutinib, lenalidomide and bortezomib have also been incorporated in an attempt to improve results [4] without success. Since the pre-rituximab era studies have incorporated high-dose therapy and autologous HSCT as part of the treatment of these lymphomas in various stages of treatment: remission induction [5-7] with results favoring the therapeutic arm of conventional chemotherapy, consolidation of remission and rescue in disease recurrence [8]. Studies and recent meta-analysis incorporating autologous HSCT as consolidation, after achieving remission in intermediate and high-risk IPI patients have not yet demonstrated evidence of benefit [911]. Sub-analyzes within these studies showed that in high-risk patients early intensification could be beneficial. In addition to IPI adverse biological characteristics such as tumor cell of origin (CGB $\times A B C)$, presence of MYC rearrangement, BCL-2 and BCL-6 (double / triple-hit) have been studied in this context with no benefit proven [12]. Aggressive NHL relapses, after initial therapy, have a poor prognosis. Rescue regimes with conventional QT, give survival rates, in two years, below $25 \%$. The PARMA TRIAL [13] randomized study demonstrated that autologous HSCT is the treatment of choice for chemosen- sitive recurrence. SLE rates, over 8 years, were $36 \%$ for the transplant arm and $11 \%$ for DHAP rescue. In the CORAL trial [14], less than $25 \%$ of patients who relapsed within 1 year of diagnosis achieved longterm disease-free survival with autologous HSCT. Final analysis of this study [15] confirmed the previous findings, in addition to demonstrating no benefit of maintenance with rituximab after autologous HSCT. In patients with DLBCL, the data on the results of allogeneic HSCT come from retrospective case series studies and record analyzes [16]. These studies included patients with very advanced disease, with several previous therapeutic lines, in addition to grouping diversified histologies, making it difficult to interpret the findings and take conclusions. Myeloblative conditioning promoted lower rates of recurrence compared to autologous $\mathrm{HSCT}$, but with unacceptably high mortality rates. Reduced intensity conditioning (RIC) have promoted the immune control of the tumor with increased survival rates and reduced transplanted-mortality related $[17,18]$.

\section{DLBCL RECOMMENDATIONS}

1.Autologous HSCT is not recommended as consolidation of remission for patients with diffuse large B-cell lymphoma, regardless of the IPI subgroup (1A)

a.Patients with partial response to R-CHOP can be considered for consolidation with ASCT

b.Patients with Double-Hit lymphomas can be considered for consolidation with ASCT if:

i.They have not received non-intensified regimens as initial therapy

ii.They have not achieved Complete Response after intensified schemes

c.DLBCL patients with secondary infiltration in the CNS can be considered for consolidation with ASCT 
with schemes targeted for central nervous central primary $\mathrm{NHL}$

2.Autologous HSCT is recommended as the therapy of choice for chemosensitive recurrence (1A); regardless of the time of recurrence.

a.There is no preferred recovery scheme, it is recommended that each center uses the scheme that is most familiar with

b.There is no maintenance benefit with post-transplant rituximab (1B)

3.Allogeneic HSCT is indicated in young patients with post-autologous recurrence using reduced intensity conditioning

\section{FOLLICULAR LYMPHOMA (FL)}

Currently, for most patients with FL without early disease-related events, survival is similar to the general population. The prognostic impact of early progression within 24 months of chemotherapy treatment (POD24), with $50 \%$ of OS in 5 years compared to $90 \%$ in patients without early progression [1-4].

The indication of early intensification in patients with $\mathrm{FL}$ in first remission was a matter of debate in the pre-rituximab era [5-8]. In the rituximab era, a randomized study comparing autologous HSCT and conventional chemotherapy and rituximab as the first line showed no difference in OS [9]. A meta-analysis published by Shaaf et al [10] confirmed the absence of benefit in OS rates, when comparing autologous HSCT to conventional chemotherapy with rituximab in previously untreated patients, as first-line therapy for FL.

The management of recurrence should be based on the time of recurrence, if early (POD24) or late. For young patients with POD24, consolidation with highdose chemotherapy and autologous HSCT should be considered [11]. In the pre-rituximab era, a randomized study (CUP Trial) demonstrated superior results for autologous HSCT compared to conventional rescue in FL [12]. Data from the CIBMTR and the National LymphoCare Study (NLCS), showed that patients who relapse less than 1 year after transplant had a higher OS at five years than those who did not undergo autologous HSCT (73\% versus $60 \%, \mathrm{P}=0.05$ ). In the multivariate analysis, the early use of autologous HSCT was associated with significantly reduced mortality (RR: $0.63 ; 95 \% \mathrm{Cl}: 0.42$ to, $94 ; \mathrm{P}=0.02$ ). [13]

Studies envolving patients with transformed FL (TFL) before the incorporation of immunotherapy demonstrate the efficacy of autologous HSCT [2,1418]. A study by the Canadian bone marrow transplant group demonstrated a modest improvement in OS and PFS for patients undergoing HSCT compared to the group of patients who had received rituximab and chemotherapy [19]. In CIBMTR analysis, the OS rate was $50 \%$ in 5 years and although a small number of patients had previously used pre-transplant rituximab, it did not impact survival rates [20]. In the PRIMA study, patients with TFL who had previously used rituximab appearead to do better when undergoing autologous HSCT. A recent study with untreated TFL patients revealed a tendency towards worse OS in the group submitted to autologous HSCT. [21, 22]

Data from retrospective studies [23], indicate a significantly lower risk of relapse for allogeneic HSCT when compared to autologous, but the benefit is suppressed by the high mortality rates related to the procedure with myeloablative conditioning. For allogeneic HSCT with reduced intensity conditioning $(\mathrm{RIC})$, the recurrence rate is generally below $30 \%$, whether or not preceded by an autologous HSCT, with a 5-year PFS ranging from 50 to 85\% [24-28]. The results of match related donors (MSD) and unrelated (MUD) in FL are similar. For patients who do not have MSD or MUD, the use of cord blood or haploidentical family donor may be considered [29-32].

\section{FL RECOMMENDATIONS}

1. Autologous HSCT is not indicated in the first line treatment of $F L(1 A)$.

2. Autologous HSCT can be considered therapy of choice in young patients with FL with early recurrence (POD24) and chemosensitive (1B).

3. Autologous HSCT should be considered in patients with TFL with chemosensitive disease, who have received therapy initially for FL (1B).

4. Allogeneic HSCT, with conditioning at reduced intensity, should be offered to patients with post-autologous recurrence and HLA-compatible donor $(2 \mathrm{C})$, preferably in chemosensitive disease.

\section{MANTLE CELL LYMPHOMA (MCL):}

Symptomatic patients or patients with a large tumor load, who have treatment indication, good performance status and permissive comorbidity profile benefit from a more intensive induction regimen with immuno-polychemotherapy through protocols that include rituximab and cytarabine. After induc- 
tion treatment, consolidation in first remission with high dose chemotherapy and autologous HSCT is recommended. This recommendation is based on restrospective case series and a prospective study from the pre-rituximab era [1-7]. Progression-free survival ranged from 48 to $68 \%$ in 4 years in these studies and overall survival from 61 to $80 \%$. The subpopulations of patients that can benefit the most are those with blastoid / pleomorphic morphology and with a high MIPI risk score. TP53 mutation carriers do not appear to benefit.

The most frequently used conditioning regime is BEAM. Alternatively, CBV, BEAC, BuCyVP [8] and BendamustinaEAM [9] have also been employed. Maintenance treatment with rituximab for 3 years after transplantation is recommended from a prospective randomized study that showed a PFS of $83 \%$ in 4 years in the Rituximab arm versus $64 \%$ in the control arm [10].

First-line regimens that include new drugs (BTK inhibitors, bortezomib, venetoclax, lenalidomide) may, in the future, replace consolidation with high doses of chemotherapy and autologous HSCT [11-13], depending on the results of prospective studies in progress.

Autologous HSCT can also be offered as a rescue treatment for chemosensitive relapses of fit patients who have not received this treatment modality as consolidation in the first line.

Evidence of an immunological effect of the graft against mantle cell lymphoma supports the indication of allogeneic HSCT in post-autologous recurrence or in first remission for selected cases [14]. Retrospective studies describe progression-free survival of 49 to $56 \%$ and overall survival of 54 to $75 \%$ in 5 years, with an incidence of $40 \%$ relapse reported in the largest series of cases, recorded by the EMBT [1517]. The conditioning regimes most frequently used were of reduced intensity.

Mostly proposed as a rescue treatment in post-autologous recurrence [18], allogeneic HSCT can be indicated in the first line for fit patients with subtypes of poor prognosis, such as those with mutated TP53 [19], blastoid or pleomorphic variants[20].

\section{RECOMMENDATIONS}

1. Autologous HSCT is indicated as consolidation in the treatment of $M C L$ that reached at least PR after the 1st line of treatment in eligible patients (2B).

2. Autologous HSCT can be considered as rescue therapy in patients with $M C L$ with chemosensitive relapses who did not receive ASCT in the first line (2B).

3. Allogeneic HSCT may be indicated for the first-line treatment of $\mathrm{MCL}$ in fit patients with poor prognosis disease, such as those with mutated TP53 or blastoid $(2 \mathrm{C})$ variants.

B. Allogeneic HSCT can be indicated as a rescue treatment in patients who relapse after autologous $\operatorname{HSCT}(2 \mathrm{C})$.

\section{PERIPHERAL T-CELL LYMPHOMAS (PTCL)}

The 2016 World Health Organization (WHO) classification recognizes up to 29 different types of PTCL [1]. The most common PTCL include peripheral T-cell lymphoma, not otherwise specified (PTCL-NOS), angioimmunoblastic T-cell lymphoma (AITL), anaplastic large cell lymphoma (ALCL, ALK-positive and ALK-negative), extranodal NK/T-cell lymphoma and other rares subtypes. Most of them have an aggressive clinical course and historically dismal results [2]. Treatment in the front-line setting is most often done with anthracycline-based chemotherapy, which is associated with a high failure rate and frequent relapses [3]. The addition of etoposide to $\mathrm{CHOP}$ results in an advantage in terms of event-free survival (EFS) but the greatest benefit was observed in young patients and ALK-positive ALCL subtype [4]. Aggressive approaches have failed to bring consistent improvements in long-term survival [5]. Currently, the better understanding of the biology of these diseases and prognostic models [6] has translated into the development of novel treatment options as brentuximab-vedotin (BV) upfront chemotherapy regimen for the PTCL CD30+, histone deacetylase inhibitor (epigenetics therapies), Janus Kinase inhibitor, phosphoinositide-3-kinase inhibitors, lenalidomide, bortezomib as therapeutics strategies $[7,8]$. Despite the availability of newer active single agents, relapsed and refractory patients are less likely to receive these therapies and continue to have inferior outcomes and improvements in front-line therapies are needed $[9,10]$. The recent publication of the ECHELON-2 trial [11] has significantly changed front-line treatment paradigms for $\mathrm{CD} 30+$ histologies, incorporing BV in front-line therapy, which includes ALK+ and ALK- ALCL, and some AITL and PTCL-NOS, demonstrated by a statistically significant improvement in PFS and OS with a manageable safety profile.

Prospective studies have demonstrated the feasibility and benefit of autologous HSCT as part of the frontline strategy in nodal PTCLs $[12,13,14]$. In the 
final analysis of the largest conducted prospective phase II trial including autologous HSCT in first remission, the Nordic study (NLG-T-01) [13], evaluated the outcomes of 166 patients, of which 62 were classified as having PTCL-NOS. This study demonstrated that $71 \%$ of patients completed the therapeutic sequence and 90 patients were in CR 3 months after transplantation. The overall response rate was $78 \%$; and at a median of 60 months, although $82 \%$ of patients had advanced disease at diagnosis. The TRM was $4 \%$. The best results were achieved for the ALKsubtype, with OS and PFS rates, in 5 years, of 70 and $61 \%$, respectively. An EBMT registry study, with a median follow-up of 65.8 months, showed a PFS rate for patients transplanted in CR/ PR was $75 \%$ compared to $32 \%$ for those transplanted with relapsed or refractory disease [15]. The COMPLETE data registry [16] was a prospective multicenter analysis of 499 patients with PTCL. Among the patients in CR following frontline therapy who underwent autologous HSCT, in of nodal types, the median OS was not reached for the autologous HSCT group, versus 57.6 weeks for the non-HSCT group, with a trend of significance $(p=0.06)$. By subgroup, there was superior survival in patients with advanced-stage and intermediate to high-risk IPI in favor of transplant. There was improved PFS and OS specifically for AITL (2-year PFS of 68.8 vs. 41.2 ) and a trend for improvement in ALK- ALCL (100 vs. 83.8), but not in PTCL NOS. This study demonstrated a trend toward improvement with autologous transplantation in PTCL. High-dose chemotherapy followed by autologous HSCT may improve the outcome in PTCL, and the achievement of a first complete remission before HSCT has proven to be a strong predictor of improved outcome $[17,18]$. High-dose therapy followed by autologous HSCT is widely recommended for consolidation after a complete or partial remission is achieved. With regard to allogeneic versus autologous transplant, a European trial randomized patients with PTCL to allogeneic versus autologous transplant and found no difference in EFS or OS. There was increased treatment-related mortality in the allogeneic group (31\%) but increased relapses (36\%) in the autologous group. At this time, there is insufficient evidence to broadly support allogeneic HSCT as part of the frontline strategy, however, reduced toxicity of allogeneic HSCT with recent advances, may alter the risk to benefit risk- benefit ratio [18]. Allogeneic HSCT is not recommended frontline other than for very rare subtypes with extremely poor outcome, such as hepatosplenic T-cell lymphoma (HSTCL) [19].

Most patients with PTCL will eventually relapse. A phase 2, open-label, multicenter study evaluated the efficacy and safety of brentuximab vedotin, for relapsed/refractory CD30+ non-Hodgkin lymphomas, and objective responses were observed in $41 \%$ of patients with relapsed T-cell lymphomas, including $54 \%$ of AITL patients [20]. There have been no prospective trials evaluating high-dose regimens of chemotherapy followed by autologous HSCT in patients with relapsed PTCL. Treatment with salvage chemotherapy and autologous HSCT may be recommended in those who are transplant eligible and did not receive a transplant in the first remission. Report of the International T-cell project demonstrated that autologous HSCT at the time of relapse was associated with a 3-year survival of $48 \%$ compared with only $18 \%$ in those without transplantation [21]. However, long-term remission rates to autologous HSCT in this setting are unsatisfactory. For the approximately $30 \%$ of patients without relapse in 2 years, the survival is significantly better (5-year OS, 78\%) [22].

Allogeneic HSCT for patients with chemo-resistant relapsed/refractory PTCL, and for those who relapse following autologous HSCT, is the only potentially curative therapy. Numerous retrospective studies have been published on this topic, relapse rates ranging range from $17 \%$ at 3 years to $49 \%$ at 5 years; NRM rates range from $12 \%$ at 5 years to $46 \%$ at 5 years; and OS rates range from $38 \%$ at 3 years to $57 \%$ at 5 years [23]. Recent studies have addressed this therapy [24-26]. As novel therapies for relapsed PTCL become available, it will be critical to combine them with allogeneic HSCT (as conditioning and/or maintenance therapies) to improve outcomes in patients with relapsed/refractory disease [27].

\section{PTCL RECOMMENDATIONS}

1.Patients with nodal PTCL, in CR/PR, should receive consolidation of remission with autologous HSCT, except ALCL ALK+ subtype (1B)

a.The remission treatment induction therapy must contain etoposide; and brentuximab-vedotin in $\mathrm{ALCL} C D 30+(2 \mathrm{~B})$

b.Autologous HSCT can be considered in second chemo-sensitive remission in ALCL ALK+ (2C)

c.Primarily refractory patients should not be transplanted with autologous HSCT (2B)

d.PET positivity found at the end of induction treatment and in patients who have received autologous HSCT is a strong predictor of reduced survival

2.ATLL: Allogeneic transplantation is the only chance to cure ATLL and is recommended for aggressive 
subtypes (acute, lymphoma type and chronic high risk) upfront for transplant-elegible patients (2B) [28]

3.HSTCL: For patients eligible, allogeneic transplantation is recommended as consolidation after induction therapy reaching CR or PR. Autologous transplant can be considered if a suitable donor is not available or the patient is not elegible for allogeneic transplant (2B) [29]

4.Allogeneic transplantation is the therapy of choice for patients with post-autologous recurrence disease $(2 \mathrm{C})$

a.Myeloablative or non-myeloablative conditioning regimens can be used

\section{REFERENCES DLBCL}

1.Coiffier B, Thieblemont C, Van Den Neste E, et AL. Long-term outcome of patients in the LNH-98.5 trial, the first randomized study comparing rituximab-CHOP to standard CHOP chemotherapy in DLBCL patients: a study by the Groupe d'Etudes des Lymphomes de l'Adulte. Blood; v. 116, n. 12, p.2040-2045, 2010.

2.Ziepert M, Hasenclever D, Kunth E, et al. Standard International prognostic index remain a valid predictor of outcome for patients with aggressive CD20+ B-cell lymphoma in the rituximab era. J Clin Oncol; v. 28, n. 14, p.2373-80, 2010.

3.Ohmachi k. JHS practical guidelines for hematological malignancies, 2018: II.Lymphoma-5diffuse large B-cell lymphoma, not otherwise specified (DLBCL,NOS). International Journal of hematol; v. 110, p.131-146, 2019.

4.Liu Y, Barta SK. Diffuse large B-cell lymphoma: 2019 update on diagnosis, risk stratification, and treatment. Am J Hematol; v. 94, p.604-616, 2019.

5.Baldissera R, Nucci M, Vigorito AC, et al. Frontline therapy with early intensification and autologous stem cell transplantation versus conventional chemotherapy in unselected high-risk, aggressive non- Hodgkin's lymphoma patients: a prospective randomized GEMOH report. Acta Haematol; v. 115, p.15-21, 2006.

6.Greb A, Bohlius J, Trelle S, et al. High-dose chemotherapy with autologous stem cell support in
b.Allogeneic HSCT is recommended frontline in hepatosplenic T-cell lymphoma due to its refractoriness to conventional chemotherapy regimens, aggressive clinical course and poor outcomes.

\section{AUTOLOGOUS CONDITIONING:}

The most commonly used protocols in autologous HSCT, for patients with lymphoma, include carmustine but in the current Brazilian reality, this medication is not marketed. Therefore, substitutes such as lomustine, bendamustine, busulfan or mitoxantrone are some of the alternatives to be associated with alkylating agents and topoisomerase inhibitors.[1-9]. The combination of gemcitabine with other drugs has also been used for lymphomas.[10-12]

the first-line treatment of aggressive non-Hodgkin ymphoma - results of comprehensive metaanalysis. Cancer Treat Rev; v. 33, n.4, p.33846, 2007.

7.Wang J, Zhan P, Ouyang J, et al. Standard chemotherapy is superior to high-dose chemotherapy with autologous stem cell transplantation on overall survival as the first-line therapy for patients with aggressive non-Hodgkin lymphoma: a meta-analysis. Med Oncol; v. 28, p.822-28, 2011.

8.Baldissera R, Bigni R, Haalack AEN et al. Hematopoietic stem cell transplantation for non-Hodgkin lymphomas. Rev Bras Hematol Hemat; v. 32 , p.106$114,2010$.

9.Stiff PJ, Unger JM, Cook JR, et al. Autologous transplantation as consolidation in aggressive non-Hodgkin's Lymphoma. N Engl J Med; v. 369, n.18, p.1681-90, 2013.

10.Chiappella A, Martelli M, Angelucci E, et al. Rituximab-dose-dense chemotherapy with or without high-dose chemotherapy plus autologous stem-cell transplantation in high-risk diffuse large B-cell lymphoma (DLCL04): final results of a multicenter, open-label, randomized, controlled, phase 3 study. Lancet Oncol; v. 18, n. 8, p.1076-1088, 2017.

11.Epperla N, Hamadani M, Religic T et al. Upfront autologous hematopoietic stem cell transplantation consolidation for patients with aggressive B-cell lymphomas in first remission in the ritux- 
imab era: A systematic review and meta-analysis. Cancer. v.125, n.24, p. 4417-4425, 2019.

12.Cabanillas F, Shah B. Advances in diagnosis and management of Diffuse Large B-cell Lymphoma. Clin Lymphoma Myeloma Leuk. v. 17, n. 12, p. 783796, 2017.

13.Philip T, Guglielmi C, Hagenbeek A et al. Autologous bone marrow transplantation as compared with salvage chemotherapy in relapses of chemotherapy-sensitive non-Hodgkin's lymphoma. NEngl J Med; . v. 33 p.1540-5, 1995.

14.Gisselbrecht C, Glass B, Mounier N, et al. Salvage regimens with autologous transplantation for relapsed large B-cell lymphoma in the rituximab era. J Clin Oncol; v. 28, p.4184-4190, 2010.

15.Gisselbrecht C, Glass B, Fournier M, et al. Salvage regimen with autologous stem cell transplantation with or without rituximab maintenance for relapsed diffuse large B-cell lymphoma (DLBCL): CORAL final report. Ann Oncol; v. 30, p.44624469, 2012.

16.Epperla $\mathrm{N}$ and Hamadani. Hematopoietic cell transplantation for diffuse large B-cell lymphoma: Current controversies and advances. Hematol Oncol Cell Ther; v. 10, n.4, p.277-284, 2017.

17.Fenske TS, Hamadani M, Cohen JB, et al. Allogeneic hematopoietic transplantation as curative therapy for patients with non-hodgkin lymphoma: Increasingly successful application to older patients. Biol Blood Marrow Transpl. v. 22, p. 1543-1551, 2016..

18.Modi D, Kim S, Surapaneni M, et al. Long term outcomes of allogeneic Transplant in diffuse large B-cell lymphoma. Blood; 132, 2018(Supplement 1) p. 5769

\section{REFERENCES FL}

19.Swenson WT, Wooldridge JE, Lynch CF, et al. Improved survival of follicular lymphoma patients in the United States. J Clin Oncol; v. 23, n. 22, p.5019-5026, 2005.

20.Maurer MJ, Bachy E, Ghesquieres H, et al. Early event status informs subsequent outcome in newly diagnosed follicular lymphoma. Am Journal of Hematol; v. 991, p.1096-1101, 2016.

21.Casulo C, Byrtek M, Dawson KL, et al. Early relapse of follicular lymphoma after rituximab plus cyclophosphamide, doxorubicin, vincristine, and prednisone defines patients at high risk for death: an analysis from the National LymphoCare Study. J Clin Oncol; v.33, p.2516-2522, 2015.

22.Jurinovic V, Kridel R, Staiger AM, et al. Clinicogenetic risk models predict early progression of follicular lymphoma after first-line immunochemotherapy. Blood; v.128, p.1112-1120, 2016.

23.Lenz G, Dreyling M, Shiegnitz E, et al. Myeloablative radio-chemotherapy followed by autologous stem cell transplantation in first remission prolongs progression-free surival in follicular lymphoma: results of a prospective, randomized trial of the German Low-Grade Lymphoma Study Group. Blood; v. 104, p.2667-2674, 2004.

24.Deconinck E, Foussard C, Milpied N, et al. High-dose therapy followed by autologous purged stem-cell transplantation and doxorubicin-based chemotherapy in patients with advanced follicular lymphoma: a randomized multicenter study by GOELAMS. Blood; v. 105, p. 2540-44, 3817-23, 2005.

25.Sebban C, Mounier N, Brousse N et al. Standard chemotherapy with interferon compared with autologous stem cell transplantation in untreated patients with advanced Follicular Lymphoma. The GELF-94 randomized study from Group d'Etude des Lymphomes de I'Adulte (GELA). Blood; v. 108, p.995-1001, 2006.

26.Gyan E, Foussard C, Bertrand P, et al. High-dose therapy followed by autologous purged stem cell transplantation and doxorubicin-based chemotherapy in patients with advanced follicular lymphoma: a randomized multicenter study by GOELAMS with final results after a median follow-up of 9 years. Blood; v. 113, p. 2009.

27.Ladetto M, De Marco F, Benedetti F, et al. Prospective, multicenter randomized GITMO/IIL trial comparing intensive (R-HDS) versus convencional (CHOP-R) chemoimunotherapy in high-risk follicular lymphoma at diagnosis: the superior disease control of R-HDS does not translate into an overall survival advantage. Blood; v. 15, p.4004-13, 2008.

28.Schaaf M, Reiser M, Borchmann P, et al. High-dose therapy with autologous stem cell transplantation versus chemotherapy or immuno-chemotherapy for follicular lymphoma in adults. Cochrane Database Syst Rev; v. 18, n.1 p.CD007678, 2012.

29.Casulo C. How I manage patients with follicular lymphoma. Br J Haematol. v.186, n.4, p. 513-523, 2019. 
30.Schouten HC, Qian W, Kvaloy S, et al. High-Dose Therapy Improves Progression-Free Survival and Survival in Relapsed Follicular Non-Hodgkin's Lymphoma: Results From the Randomized European CUP Trial. J Clinical Oncology; v. 186, n. 4. p.39183927, 2003.

31.Casulo C, Friedberg JW, Ahn KW, et al. Autologous transplantation in follicular lymphoma with early therapy failure: a National LymphoCare Study and Center for International Blood and Marrow Transplant Research Analysis. Biol Blood Marrow Transplant; v. 21, p.1163-1171, 2017.

32.Bernstein SH, Burack WR. The incidence, natural history, biology, and treatment of transformed lymphomas. Hematology Am Soc Hematol Educ Program; p.532-541, 2009.

33.Hamadani M, Benson DM Jr, Lin TS, et al. Highdose therapy and autologous stem cell transplantation for follicular lymphoma undergoing transformation to diffuse large B-cell lymphoma. Eur J Haematol; v.81, n. 6, p.425-431, 2008.

34.Williams CD, Harrison CN, Lister TA, et al. European Bone Marrow Transplant Lymphoma Working Party. High-dose therapy and autologous stemcell support for chemosensitive transformed low-grade follicular non-Hodgkin's lymphoma: a case-matched study from the European Bone Marrow Transplant Registry. J Clin Oncol; v.19, n.3, p.727-735, 2001.

35.Chen $\mathrm{Cl}$, Crump $\mathrm{M}$, Tsang $\mathrm{R}$, Stewart AK, Keating A. Autotransplants for histologically transformed follicular non-Hodgkin's lymphoma. Br J Haematol. 2001;113(1):202-208. 52. Friedberg JW, Neuberg D, Gribben JG, et al. Autologous bone marrow transplantation after histologic transformation of indolent $B$ cell malignancies. Biol Blood Marrow Transplant; v. 5, n.4, p.262-268, 1999.

36.Sabloff M, Atkins HL, Bence-Bruckler I, et al. A 15-year analysis of early and late autologous hematopoietic stem cell transplant in relapsed, aggressive, transformed, and nontransformed follicular lymphoma. Biol Blood Marrow Transplant; v. 13, n.8, p.956-964, 2007.

37.Villa D, Crump M, Panzarella T, et al. Autologous and allogeneic stem-cell transplantation for transformed follicular lymphoma: a report of the Canadian blood and marrow transplant group. $J$ Clin Oncol; v.31, n.9, p.1164-1171, 2013.
38.Wirk B, Fenske TS, Hamadani M, et al. Outcomes of hematopoietic cell transplantation for diffuse large B cell lymphoma transformed from follicular lymphoma. Biol Blood Marrow Transplant; v. 20, n.7, p.951-959, 2014.

39.Sarkozy C, Trneny M, Xerri L, et al. Risk Factors and Outcomes for Patients With Follicular Lymphoma Who Had Histologic Transformation After Response to First-Line Immunochemotherapy in the PRIMA TrialJ Clin Oncol; v.34, p.2575-2582, 2016.

40.Chin CK, Lim KJ, Lewis K, et al. Autologous Stem Cell Transplantation for Untreated Transformed Indolent B-Cell Lymphoma. Br J Haematol 2020, doi: 10.1111/bjh.17072

41.Foster M, Gabriel, DA, Shea T. Role of hematopoietic stem cell transplant in the management of follicular lymphoma. Oncologist; v.14, p.726-738, 2009.

42. Hari P, Carreras J, Zhang MJ, et al. Allogeneic transplants in follicular lymphoma: higher risk disease progression after reduced-intensity compared to myeloablative conditioning. Biol Blood Marrow Transplant; v.14, n.2, p.236-45, 2008.

43.Khouri IF, McLaughlin P, Saliba RM, et al. Eightyear experience with allogeneic stem cell transplantation for relapsed follicular lymphoma after nonmyeloablative conditioning with fludarabine, cyclophosphamide and rituximab. Blood; v. 11, p.5530-6, 2008.

44.Laport G, Bredeson CN, Tomblyn M, et al. Autologous versus reduced intensity allogeneic hematopoietic cell transplantation for patients with follicular non-Hodgkin's lymphoma (FL) beyond first complete response or first partial response [abstract 7041]. J. Clin. Oncol; p.26, 2008.

45.Robinson SP, Boumendil A, Finel $\mathrm{H}$, et al. Reduced intensity allogeneic stem cell transplantation for follicular lymphoma relapsing after an autologous transplant achieves durable long term disease control. An analysis from the Lymphoma Working Party of the EBMT. Ann Oncol; v. 27, p.1088, 2016.

46. Robinson SP, Canals C, Luang JJ, et al. The outcome of reduced intensity allogeneic stem cell transplantation and autologous stem cell transplantation when performed as a first transplant strategy in relapsed follicular lymphoma: an analysis from the Lymphoma Working Party of the EBMT. Bone Marrow Transplant; v. 48, p.140914, 2013. 
47.Sureda A, Zhang M-J, Dreger P, et al. Allogeneic hematopoietic stem cell transplantation for relapsed follicular lymphoma. A combined analysis on behalf of the Lymphoma Working Party of the EBMT and the Lymphoma Committee of the CIBMTR. Cancer; v.124, p.1733-42, 2018.

48. Rodrigues CA, Sanz G, Brunstein CG, et al. Analysis of risk factors for outcomes after unrelated cord blood transplantation in adults with lymphoid malignancies: a study by the Eurocord-Netcord and lymphoma working party of the European group for blood and marrow transplantation. J Clin Oncol; v.27, p.256-63, 2009.

49.Brunstein CG, Cantero S, Cao Q, et al. Promising progression-free survival for patients low and intermediate grade lymphoid malignancies after nonmyeloablative umbilical cord blood transplantation. Biol Blood Marrow Transplant; v.15, p.214-22, 2009.

50.Dietrich S, Finel H, Martinez C, et al. Post-transplant cyclophosphamide-based haplo-identical transplantation as alternative to matched sibling or unrelated donor transplantation for non-Hodgkin lymphoma: a registry study by the European society for blood and marrow transplantation. Leukemia; v.30, p.2086-9, 2016.

\section{REFERENCES MCL}

51.Khouri IF, Romaguera J, Kantarjian H, Palmer $J L$, Pugh WC, Korbling M, et al. Hyper-CVAD and high-dose methotrexate/ cytarabine followed by stem-cell transplantation: an active regimen for aggressive mantle-cell lymphoma. J Clin Oncol; v. 16, n. 12, p.3803-9, 1998.

52.Vandenberghe $E$, Ruiz de Elvira C, Loberiza FR, Conde E, LopezGuillermo A, Gisselbrecht C, et al. Outcome of autologous transplantation for mantle cell lymphoma: a study by the European blood and bone marrow transplant and autologous blood and marrow transplant registries. $\mathrm{Br}$ J Haematol; v. 120, n. 5, p.793-800, 2003.

53.Tam CS, et al. Mature results of the M. D. Anderson Cancer Center risk-adapted transplantation strategy in mantle cell lymphoma. Blood; v. 113, n. 18, p.4144-52, 2009.

54.Decaudin D, Brousse N, Brice P, Haioun C, Bourhis JH, Morel P, et al. Efficacy of autologous stem cell transplantation in mantle cell lymphoma: a 3-year follow-up study. Bone Marrow Transplant; v. 25, n.3, p.251-6, 2000.
55.Milpied N, Gaillard F, Moreau P, Mahé B, Souchet J, Rapp MJ, et al. High-dose therapy with stem cell transplantation for mantle cell lymphoma: results and prognostic factors, a single center experience. Bone Marrow Transplant; v. 22, n.7, p.645-50, 1998.

56.Sawalha $Y$, et al. The role of upfront autologous hematopoietic cell transplantation in the treatment of mantle cell lymphoma, a population based study using the National Cancer Data Base (NCDB). Blood; v.130, p. 2009, 2017.

57.Gerson JN, Handorf E, Villa D, Gerrie AS, Chapani $\mathrm{P}$, Li S, et al. Survival outcomes of younger patients with mantle cell lymphoma treated in the rituximab era. J Clin Oncol; v. 37, n.6, p.471-80, 2019.

58. Hueso T, Gastinne T, Garciaz S, et al. Bendamustine-EAM versus BEAM regimen in patients with mantle cell lymphoma undergoing autologous stem cell transplantation in the frontline setting: a multicenter retrospective study from Lymphoma Study Association (LYSA) centers. Bone Marrow Transplantation; v. 55, n.6, p.1076-1084, 2020.

59.Singer S, Sharma N, Dean R, et al. BEAM or BUCYVP16-conditioning regimen for autologous stem-cell transplantation in non-Hodgkin's lymphomas. Biol Blood Marrow Transplant; v. 25. n. 6. p.1107-1115, 2019.

60.Le Gouill S, et al. Rituximab after autologous stem-cell transplantation in mantle-cell lymphoma. NEng/ J Med. v. 377, n.13, p. 1250-1260, 2017.

61.Robak T, Huang H, Jin J, Zhu J, Liu T, Samoilova $\mathrm{O}$, et al. Bortezomib-based therapy for newly diagnosed mantle-cell lymphoma. N Engl J Med; v. 372, n. 10, p.944-53, 2015.

62.Ruan J, Martin P, Shah B, Schuster SJ, Smith SM, Furman RR, et al. Lenalidomide plus rituximab as initial treatment for mantlecell lymphoma. $N$ Engl J Med; v.373, n. 19, p.1835-44 2015.

63.Ruan J, et al. Five-year follow-up of lenalidomide plus rituximab as initial treatment of mantle cell lymphoma. Blood; v. 132, n. 19, p.2016-25, 2018.

64.Khouri IF, LeeMS, Romaguera J,Mirza N, Kantarjian $\mathrm{H}$, Korbling $\mathrm{M}$, et al. Allogeneic hematopoietic transplantation for mantle-cell lymphoma: molecular remissions and evidence of graft-versus-malignancy. Ann Oncol;1999. 
65.Rule S, et al. Allogeneic stem cell transplantation as part of front line therapy for mantle cell lymphoma. Br J Haematol. 2018.

66.Sandoval-Sus JD, et al. Allogeneic hematopoietic cell transplantation is potentially curative in mantle cell lymphoma: results from a single institution study. Leuk Lymphoma. p. 1-8, 2018.

67.Robinson SP, Boumendil A, Finel H, Peggs KS, Chevallier P, Sierra J, et al. Long-term outcome analysis of reduced-intensity allogeneic stem cell transplantation in patients with mantle cell lymphoma: a retrospective study from the EBMT Lymphoma Working Party. Bone Marrow Transplant; v.53, n. 5, p.617-24, 2018.

68.Tessoulin B, et al. Allogeneic stem cell transplantation for patients with mantle cell lymphoma who failed autologous stem cell transplantation: a national survey of the SFGM-TC. Bone Marrow Transplant; v. 51, n.9, p.1184-90, 2016.

69.Lin RJ, Ho C, Hilden PD, Barker JN, Giralt SA, Hamlin PA, et al. Allogeneic haematopoietic cell transplantation impacts on outcomes of mantle cell lymphoma with TP53 alterations. Br J Haematol. 2018.

70.Dreyling M, Klapper W, Rule S. Blastoid and pleomorphic mantle cell lymphoma: still a diagnostic and therapeutic challenge! Blood; v. 132, n. 26, p.2722-9, 2018.

\section{REFERENCES PTCL}

71.Swerdlow SH, Campo E, Pileri SA, et al. The 2016 revision of the World Health Organization classification of lymphoid neoplasms. Blood; v. 127, p.2375-2390, 2016.

72.Mak V, Hamm J, Chhanabhai M, et al. Survival of patients with peripheral T-cell lymphoma after first relapse or progression: spectrum of disease and rare long-term survivors. JCO; v.16, p.1970-6, 2013.

73.Abouyabis NA, Shemoy PJ, Sinha R, et al. A Systematic Review and Meta-Analysis of Front-line Anthracycline-Based Chemotherapy Regimens for Peripheral T-Cell Lymphoma. ISRN Hematol, Epub jun 2011.

74.Schmitz N, Trümper L, Ziepert $M$, et al. Treatment and prognosis of mature T-cell and NK-cell lymphoma: an analysis of patients with T-cell lymphoma treated in studies of the German High-Grade Non-Hodgkin Lymphoma Study Group. Blood; v.116, n.18, p.3418-25, 2010.
75.Moskowitz AJ, Lunning MA, Horwitz SM. How I Treat Peripheral T-cell Limphomas. Blood; v. 123, p.2636-2644, 2014.

76.Roy AM, Pandey $Y$, Konda $M$, et al. Treatment strategies and outcomes for patients with peripheral T-cell lymphoma and its subtypes. Blood; v.136, p. 2020.(supplement) p. 36-37.

77.Bachy E, Broccoli A, Dearden C, et al. Controversies in the treatment of peripheral T-cell lymphoma. Hemasphere. v.4, n.5, p.461, 2020.

78.Zain JM. Aggressive T-cell lymphomas: 2019 updates on diagnosis, risk stratification, and management. Am J Haematol; v. 94, n. 8, p.929-946, 2019.

79.Stuver RN, Khan N, Schwarts M, et al. Single agent versus combination chemotherapy in relapsed and refractory peripheral T-cell lymphoma: results fron the comprehensive oncology measures for peripheral t-cell lymphoma treatment (COMPLETE) registry. Am J Hematol; v. 94, n. 6, p.641649, 2019.

80.Lansigan F, Horwitz SM, Pinter-Brown L, et al. Outcomes for relapsed and refractory peripheral T-cell lymphoma patients after front-line therapy from the COMPLETE Registry. Acta Haematol; v. 143, n. 1, p.40, 2020.

81. Horwitz S, O'Connor AO, Pro B, et al. Brentuximab vedotin with chemothepay for CD-30-positive peripheral T-cell lymphoma (ECHELON-2): a global, double-blind, randomized, phase-3 trial. Lancet; v. 393, p.229-240, 2019.

82.Reimer P, Rudiger T, Geissinger E, et al. Autologous stem-cell transplantation as first-line therapy in peripheral T-cell lymphomas: results of a prospective multicenter study. J Clin Oncol; v. 27, n. 1, p.106-13, 2009.

83.d'Amore F, Relander T, Lauritzsen GF, et al. Highdose chemotherapy and autologous stem cell transplantation in previously untreated peripheral T-cell lymphoma - final analysis of a large prospective multicenter study (NLG-T-01). JCO; v. 30, p.3093-99, 2012.

84.Ellin F, Landstrom J, Jerkeman M, Relander T. Real-world data on prognostic factors and treatment in peripheral T-cell lymphomas: a study from the Swedish Lymphoma Registry. Blood; v.124, n. 10, p.1570-7, 2014.

85.Nademanee A, Palmer JM, Popplewell L, et al. 
High-dose therapy and autologous hematopoietic transplantation in peripheral T cell Lymphoma (PTCL): analysis of prognostic factors. Biol Blood marrow Transplant; v. 17, p.1481-89, 2011.

86.Park SI, Horwitz SM, Foss FM, et al. The role of autologous stem cell transplantation in patients with nodal peripheral T-cell lymphomas in first complete remission: Report from COMPLETE, a prospective, multicenter cohort study. Cancer; v. 125, n. 9, p.1507-17, 2019.

87.Abramson JS, Feldman T, Kroll-Desrosiers AR, et al. Peripheral T-cell lymphomas in a large US multicenter cohort: prognostication in the modern era including impact of frontline therapy. Ann Oncol; v. 25, n. 11, p.2211-7, 2014.

88. Tournilhac O, Truemper L, Ziepert M, et al. Firstline therapy of Tcell lymphoma: allogeneic or autologous transplantation for consolidation final results of the AATT study. Hematol Oncol; v. 37. n. s2, p.99-101, 2019.

89.d'Amore F, Gaulard P, Trümper L, et al. ESMO Guidelines Committee Peripheral T-cell lymphomas: ESMO Clinical Practice Guidelines for diagnosis, treatment and follow-up. Ann Oncol; v.26, Suppl 5, p.108-115, 2015.

90. Horwitz SM, Advani RH, Bartlett NL, et al. Objective responses in relapsed T-cell lymphomas with single-agent brentuximab vedotin. Blood. v. 123, n.20, p. 3095-100, 2014 ..

91.Bellei M, Foss FM, Shustov AR, et al. The outcome of peripheral Tcell lymphoma patients failing first-line therapy: a report from the prospective, International T-Cell Project. Haematologica; v. 103, n. 7, p.4019-26, 1191-7, 2018.

92.Maurer MJ, Ellin F, Srour L, et al. International assessment of event-free survival at 24 months and subsequent survival in peripheral T-cell lymphoma. J Clin Oncol; v. 35, n. 36. p.4019-26, 2017.

93.Rogers AM \& Brammer JE. Hematopoietic cell transplantation and adoptive cell therapy in peripheral T-cell lymphoma. Curr Hematol Malignant Reports 2020.

94.Schmitz N, Lenz G, Stelljes M. Allogeneic hematopoietic stem cell transplantation for T-cell lymphomas. Blood. v.132,n. 3, p. 245-253, 2018..

95.Epperla N, Ahn KW, Litovich C, et al. Allogeneic hematopoietic cell transplantation provides effective salvage despite refractory disease or failed prior autologous transplant in angioimmunoblastic T-cell lymphoma: a CIBMTR analysis. J Hematol Oncol. v.12, n.1, p.6, 2019.

96.Rohlfing $S$, Dietrich $S$, Witzens-Harig $M$, et al. The impact of stem cell transplantation on the natural course of peripheral T-cell lymphoma: a real-world experience. Ann Hematol; v. 97, n. 7, p.1241-50, 2018.

97.Champlin RE, Andersson BS, Popat UR, Hosing CM. Romidepsin (Rom) in combination with fludarabine (Flu) and busulfan (Bu) conditioning followed by Rom maintenance in patients with T-cell malignancies receiving allogeneic stem cell transplant (allo-SCT): early results of a phase I/ II trial. Biol Blood Marrow Transplant; v. 24, 2018. Abstract 343.

98.Tsukasaki K, Marçais A, Nasr R, Kato K, Fukuda T, Hermine O, Bazarbachi A. Diagnostic Approaches and Established Treatments for Adult T Cell Leukemia Lymphoma.Front Microbiol; v. 19, n. 11 p.1207, 2020.

99. Horwitz SM, Ansell S, Ai WZ, et al. NCCN Guidelines Insights: T-Cell Lymphomas, Version 1.2021. J Natl Compr Canc Netw; v. 18, n. 11, p.1460-1467, 2020.

\section{REFERENCES CONDITIONING}

100.Chen YB, AL Andrew, Logan B.R., et al. Impact of Conditioning Regimen on Outcomes for Patients with Lymphoma Undergoing High-Dose Therapy with Autologous Hematopoietic Cell Transplantation. Biology of Blood Marrow Transplantantion. v.21, p. 1046-1053, 2015.

101.Chao NJ, Kastrissios H, Long GD, et al. A New Preparatory Regimen for Autologous Bone Marrow Transplantation for Patients with Lymphoma. Cancer; v. 75, p.1354-59, 1995.

102.Santos KB, Costa LJ, Atalla A, et al. The lomustine use in combination with etoposide, cytarabine and melphalan in a brief conditioning for auto-HSCT in patients with lymphoma: the optimal dose. Bone Marrow Transplantation; v. 49, p.1239-40, 2014.

103.Santos KB, Costa LJM, Bettarello B, et al. LEAM versus $C B V$ for conditioning in autologous hematopoietic stem cell transplantation for lymphoma. Bone Marrow Transplanttion; v. 54, p.625-28, 2019.

104.Visani G, Malerba L, Stefani PM, et al. BeEAM 
(bendamustine, etoposide, cytarabine, melphalan) before autologous stem cell transplantation is safe and effective for resistant/relapsed lymphoma patients. Blood; v. 118, p.3419-3425, 2011.

105.Jaimovich G, Ostriz MBR, Castro M et al. CBeV (cyclophosphamide, bendamustine and etoposide) pre-autotransplant conditioning in persons with lymphoma. Bone Marrow Transplantation; v. 55, p.265-67, 2020.

106. Hueso T, Gastinne T, Garcaiz S, et al. Bendamustine-EAM versus BEAM regimen in patients with mantle cell lymphoma undergoing autologous stem cell transplantation in the frontline setting: a multicenter retrospective study from Lymphoma Study Association (LYSA) centers. Bone Marrow Transplantation; v. 55, p.1076-84, 2020.

107.Aggarwal C, Gupta S, Vaughan WP, et al. Improved Outcomes in Intermediate- and HighRisk Aggressive Non-Hodgkin Lymphoma after Autologous Hematopoietic Stem Cell Transplantation Substituting Intravenous for Oral Busulfan in a Busulfan, Cyclophosphamide, and Etoposide Preparative Regimen. Biology of Blood and Marrow Transplantation; v.12, p.770-77, 2006.
108.Kim J, Lee HJ, Yi HG, el al. Mitoxantrone, etoposide, cytarabine, and melphalan (NEAM) followed by autologous stem cell transplantation for patients with chemosensitive aggressive non-Hodgkin lymphoma. American Journal of Hematology; v.87, Issue 5,p.479-483.

109.Nieto Y, Thall P, Valdez B, et al. High-Dose Infusional Gemcitabine Combined with Busulfan and Melphalan with Autologous Stem-Cell Transplantation in Patients with Refractory Lymphoid Malignancies. Biology of Blood and Marrow Transplantation; v.18, p.1677-86, 2012.

110.Nieto $\mathrm{Y}$, Basset $\mathrm{R}$, Anderlini $\mathrm{P}$, et al. Prospective Phase 2 Trial of High-Dose Gemcitabine/Busulfan/Melphalan (Gem/Bu/Mel) with Autologous Stem-Cell Transplant (ASCT) without Post-ASCT Maintenance, in Hodgkins Lymphoma Patients at High Risk of Post-Transplant Recurrence Comparison with a Concurrent Matched Cohort Treated with BEAM. Blood; v.126, n.23, p.1980, 2015.

111.Davidson M, Stewart DA, Duggan P, et al. Phase I/II Study of Infusional Gemcitabine and High-Dose Melphalan Conditioning Prior to Autologous Stem Cell Transplantation for Patients with Relapsed/Refractory Lymphoma: Interim Safety Analysis. Blood; v. 18, n.130, p.4534, 2017. 